\title{
Erratum to: Ethics review of studies during public health emergencies - the experience of the WHO ethics review committee during the Ebola virus disease epidemic
}

Emilie Alirol ${ }^{1}$, Annette C. Kuesel ${ }^{2 *}$, Maria Magdalena Guraiib ${ }^{3}$, Vânia de la Fuente-Núñez ${ }^{3}$, Abha Saxena ${ }^{3}$ and Melba F. Gomes ${ }^{4}$

\section{Erratum}

After publication of the article [1], it has been brought to our attention that an author's name has been included incorrectly. The correct name is "Vânia de la FuenteNúñez". The original version of the article has been revised to reflect this.

\begin{abstract}
Author details
'Global Antibiotics Research and Development Partnership (GARDP), Drugs for Neglected Diseases initiative (DNDi), 15 chemin Louis Dunant, 1202 Geneva, Switzerland. 'World Health Organization, UNICEF/UNDP/World Bank/ WHO Special Programme for Research and Training in Tropical Diseases, 20 Avenue Appia, 1211, 27, Geneva, Switzerland. 'World Health Organization, Department for Information Evidence and Research, 20 Avenue Appia, 1211, 27, Geneva, Switzerland. 'World Health Organization, 20 Avenue Appia, 1211, 27, Geneva, Switzerland.
\end{abstract}

Received: 5 July 2017 Accepted: 6 July 2017

Published online: 12 July 2017

\section{Reference}

1. Alirol E, Kuesel A, Guraiib M, dela Fuente-Núñez V, Saxena A, Gomes M. Ethics review of studies during public health emergencies - the experience of the WHO ethics review committee during the Ebola virus disease epidemic. BMC Medical Ethics. 2017;18:1. doi:10.1186/s12910-017-0201-1.

* Correspondence: kuesela@who.int

2World Health Organization, UNICEF/UNDP/World Bank/ WHO Special

Programme for Research and Training in Tropical Diseases, 20 Avenue Appia,

1211, 27, Geneva, Switzerland 